\title{
Predicting the potential distributions of the invasive cycad scale Aulacaspis yasumatsui (Hemiptera: Diaspididae) under different climate change scenarios and the implications for management
}

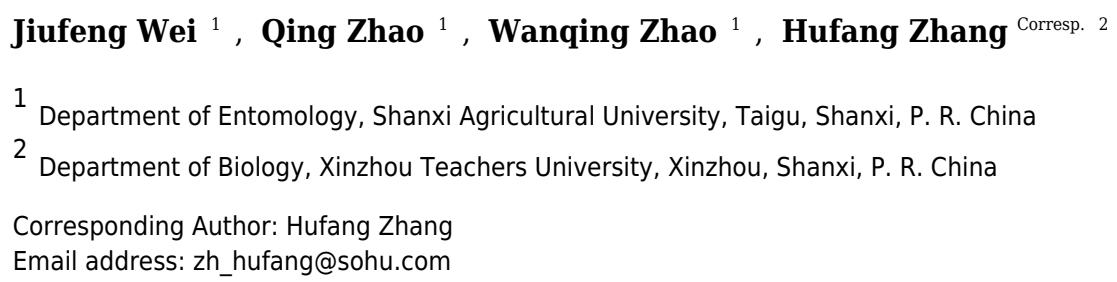

Cycads are an ancient group of gymnosperms that are popular as landscaping plants, though nearly all of them are threatened or endangered in the wild. The cycad aulacaspis scale (CAS), Aulacaspis yasumatsui Takagi (Hemiptera: Diaspididae), has become one of the most serious pests of cycads in recent years; however, the potential distribution range and the management approach for this pest are unclear. A potential risk map of cycad aulacaspis scale was created based on occurrence data under different climatic conditions and topology factors in this study. Furthermore, the future potential distributions of CAS were projected for the periods 2050s and 2070s under three different climate change scenarios (GFDL-CM3, HADGEM2-AO and MIROC5) described in the Special Report on Emissions Scenarios of the IPCC (Intergovernmental Panel on Climate Change). The model suggested high environmental suitability for the continents of Asia and North America, where the species has already been recorded. The potential distribution expansions or reductions were also predicted under different climate change conditions. Temperature of Driest Quarter (Bio9) was the most important factor, explaining $48.1 \%$ of the distribution of the species. The results also suggested that highly suitable habitat for CAS would exist in the study area if the mean temperature of $15-20^{\circ} \mathrm{Cin}$ the driest quarter and a mean temperature of $25-28{ }^{\circ} \mathrm{C}$ in the wettest quarter. This research provides a theoretical reference framework for developing policy to manage and control this invasive pest. 
1 Predicting the potential distributions of the invasive cycad scale Aulacaspis yasumatsui

2 (Hemiptera: Diaspididae) under different climate change scenarios and the implications for

3 management

4

5 Jiufeng $\mathrm{Wei}^{1^{*}}$, Qing Zhao ${ }^{1^{*}}$, Wanqing Zhao ${ }^{1}$, and Hufang Zhang ${ }^{2}$

$6{ }^{1}$ Department of Entomology, Shanxi Agricultural University, Taigu, Shanxi, P.R. China

$7 \quad{ }^{2}$ Department of Biology, Xinzhou Teachers University, Xinzhou, Shanxi, P. R. China

8

$9 \quad *$ These authors contributed equally to this work.

10 Corresponding author. Hufang Zhang, zh_hufang@sohu.com

11

12

13

14

15

16

17

18

19

20

21

22

23

24

25 


\section{ABSTRACT}

28

29

30

31

32

33

34

35 36

37

38

39

40

41

42

43

44

45

46

47

48

49

50

51

52

53

\section{5}

Cycads are an ancient group of gymnosperms that are popular as landscaping plants, though nearly all of them are threatened or endangered in the wild. The cycad aulacaspis scale (CAS), Aulacaspis yasumatsui Takagi (Hemiptera: Diaspididae), has become one of the most serious pests of cycads in recent years; however, the potential distribution range and the management approach for this pest are unclear. A potential risk map of cycad aulacaspis scale was created based on occurrence data under different climatic conditions and topology factors in this study. Furthermore, the future potential distributions of CAS were projected for the periods 2050s and 2070s under three different climate change scenarios (GFDL-CM3, HADGEM2-AO and MIROC5) described in the Special Report on Emissions Scenarios of the IPCC (Intergovernmental Panel on Climate Change). The model suggested high environmental suitability for the continents of Asia and North America, where the species has already been recorded. The potential distribution expansions or reductions were also predicted under different climate change conditions. Temperature of Driest Quarter (Bio9) was the most important factor, explaining $48.1 \%$ of the distribution of the species. The results also suggested that highly suitable habitat for CAS would exist in the study area if the mean temperature of $15-20^{\circ} \mathrm{Cin}$ the driest quarter and a mean temperature of $25-28{ }^{\circ} \mathrm{C}$ in the wettest quarter. This research provides a theoretical reference framework for developing policy to manage and control this invasive pest. 
INTRODUCTION

57

58

59

60

61

62

63

64

65

66

67

68

69

70

71

72

73

74

75

76

77

78

79

80

81

82

83

84

Invasive species threaten native ecosystems through interspecific competition with native species, but they also threaten human-managed systems, such as those related to agriculture, animal health and forestry (Bradley, Wilcove \& Oppenheimer, 2000; Simberloff et al., 2003). Considerable evidence has shown that climate change will aggravate the impacts of the naturalization and subsequent invasion of invasive species into novel communities and ecosystems (Walsh, Carpenter \& Zanden, 2016; Ekesi et al., 2016; Paini et al., 2016). Moreover, rising temperatures can significantly influence the physiological characteristics of insect lift history and population dynamics, such as development rate, voltinism and distribution range (Bellard et al., 2013; Yousuf et al., 2014; Duan et al., 2014). Understanding the change in potential distribution due to climate change is a critical foundation that is required to manage and control the introduction of alien species (Massin et al., 2012).

Cycads (Cycadales), commonly called "sago palms", are considered as the most primitive extant seed plant lineage and are often characterized as "living fossils" (Marler \& Moore, 2010) due to their long evolutionary history (Brenner, Stevenson \& Twigg, 2003; Salas-Leiva et al., 2013). There are 348 extant species of cycads, and almost all are threatened or endangered (Normark et al., 2017). At present, cycads are popular landscape plants in tropical and subtropical areas because they are long-lived and require little maintenance (Bailey et al., 2011). However, many cycad species, such as Cycad micronesica, are facing extinction in the wild due to insect pests (eg., the cycad blue butterfly) (Wu et al., 2010) and microbial pathogens (Nesamari et al., 2015). The cycad aulacaspis scale (CAS), Aulacaspis yasumatsui Takagi (Hemiptera: Diaspididae), is one of the serious pest of cycads (Giorgi \&Vandenberg, 2012).

Studies have suggested that this highly invasive species poses a threat to costly ornamental and horticultural plants, but it also damages wild cycad populations, including plants in conservation areas around the world (Marler \& Lawrence, 2012). The CAS was first described from specimens collected in Bangkok, Thailand in 1972 by Takagi (Takagi, 1977), but the species usually occurs at low densities in its native range due to control by natural enemies (Tang, Yang \& Vatcharakorn, 1997; Marler \& Moore, 2010). To date, the CAS has spread to many areas outside of its native range. The first report of CAS on cycads outside Thailand was in 1996 in 
85 Florida, USA, where it infested ornamental plants and killed large numbers of king sago, Cycas 86 revoluta Thunberg (Howard et al., 1999); it was subsequently found in the Fairchild Tropical 87 Garden and the Montgomery Botanical Center, both of which have collections of rare and 88 endangered cycads. Following its introduction in Florida, the CAS spread to Alabama, Georgia, 89 Louisiana, South Carolina, and Texas (Haynes, 2005) and most recently, this pest was also reported in Mexico (González-Gómez et al., 2016; Normark et al., 2017). The CAS has now been introduced to many countries including China (Bailey et al., 2010), Singapore (Hodgson \& Martin, 2001),Vietnam (EPPO, 2014) and Philippines in Asia; Guam (Terry \& marler, 2005), the Cayman Islands, Puerto Rico, the Vieques Islands, and the Hawaiian Islands in the Americas; as well as in Africa (Nesamari et al., 2015); and Europe (Malumphy \& Marquart, 2012); among other locations. Moreover, CAS was intercepted several times from France in 2001 (Germain, 2002).

Due to the damage caused by CAS, many cycads in southern Miami, area of Florida, died within a year, and mature cycads were killed in a matter of months (Walters, Shroyer \& Anderson, 1997; Howard et al., 1999). Some endemic cycads, such as Cycas micronesica in Guam (Marler \& Lawrence, 2012) and Cycas taitungensis in Taiwan (Bailey, Chang \& Lai, 2011) are threatened with extinction due to CAS. The pest feeds on both the aerial parts of host cycads but also on their roots (Takagi \& De faveri, 2009), and at the start of an infestation, damage initially appears as chlorotic spots on the undersides of leaves. As the infestation progresses, CAS infests the upper surfaces of the leaf and then occurs on the petioles as well as the stems and as the population density of the scale increases, infested plants become quickly and almost completely covered by live and dead scales and appear as enveloped a white crust (Emshousen, Mannion \& Glenn, 2004). CAS is very harmful to cycads, causing death as well as reducing their ornamental value (Milek, Šimala \& Novak, 2008).

Currently, at least 8 genera from 3 different families of cycads are threatened by CAS (García et al., 2017), and there is an urgent need to control and manage this pest due to its rapid spread and wide host range. If this pest is not managed or controlled, it poses a threat to the ornamental cycad nursery industry and may accelerate the extinction of wild cycads (Emshousen, Mannion \& Glenn, 2004).

4 Based on empirical data from Florida and other regions, it is difficult to control CAS through any of the currently available methods (Muniappan et al., 2012). Therefore, an alternative approach is to enforce strict quarantine measures in countries where CAS has not yet 
117 been introduced by prohibiting the importation of cycad plants from infested countries.

118 Information regarding the potential distribution of this species under climate change will be

119 indispensable for scientists and farmers around the world to develop future monitoring and 120 management strategies for this pest (Jimenez-Valverde et al., 2011). In this paper, the current and

121 future potential distributions of CAS were estimated based on available occurrence data using

122 MaxEnt software. The mainly objectives were (1) to identify the main climatic variable that

123 constrains the potential distribution of CAS, (2) to predict the trends of its suitable habitat range

124 under different climatic change scenarios, and (3) to provide a theoretical reference framework

125 for developing policy to manage and control this invasive pest.

126 MATERIALS AND METHODS

\section{Species data}

128 The occurrence data for CAS were compiled from three main sources: the Centre for 129 Agriculture and Bioscience International (CABI, https://www.cabi.org/), the Global Biodiversity 130 Information Facility (GBIF, https://www.gbif.org/) and the existing literature (Table S1). Geo131 coordinates for each chosen data-point were either referenced from information in the literature 132 or by using Google Earth coordinates. Duplicate or unclear locations were excluded, and data 133 were manually checked for accuracy.

134 Occurrence records are often biased towards areas where assemblages are easily accessible, 135 such as near cities or other areas with high population density (Kadmon, Farber \& Danin, 2004); 136 therefore, occurrence data can significantly impacts the modelling results of the model (Elith et 137 al., 2011). To minimize sampling bias and remove spatial autocorrelation, a coarse resolution (5 $138 \mathrm{~km} \times 5 \mathrm{~km}$ ) was created using the workflow of $L i, D u \& G u o$ (2015) and a single point was 139 randomly selected from each cell containing one or more sampling points (Rodriguez-Castaneda 140 et al., 2012). The workflow was conducted in ArcGIS 10.1 (ESRI, Redlands, CA, USA. 141 http://www.esri.com/), and after filtering, 94 locations remained, including the native range (6 142 points) and the invaded regions in North America (59 points), Europe (7 points), Asia (16 points) 143 and Africa (6 points). The list of distribution sites is shown in Fig.1 and Table S2.

\section{Environmental variables}

145 The environmental variables used to characterize ecological niches were selected 146 considering the climate and topography. Climatic variables are probably the main determinant of 
147 species niches at large scale (Luoto, Virkkala \& Heikkinen, 2007), and they have previously been

148 used for insect niche modelling (Medley, 2010). All environmental variables used in this study 149 were download from the WorldClim Global Climate Database (http:/www.worldclim.org) 150 (Hijmans et al., 2005), and current climate conditions were represented by minima, maxima and 151 average values of monthly, quarterly and annual ambient temperatures as well as precipitation 152 values recorded from 1950-2000. These parameters provided a combination of means, extremes 153 and seasonal differences in variables known to influence species distribution (Root, Price \& 154 Hall, 2003). Topographic variables represented by altitude (ALT) were derived from HYDRO1K 155 (Http://eros.usgs.gov). Multicollinearity among predictor variables may hamper the analysis of 156 species-environment relationships (Heikkinen et al., 2006). Thus, principal component analysis 157 (PCA) in SPSS Statistics was performed to remove highly correlated variables ( $\mathrm{r} \geq|0.85|$ ) (Table 158 S3). Finally, six climatic environmental and topographic variables were selected: Mean Diurnal 159 Range (Mean of monthly (max temp - min temp)) (Bio2), Mean Temperature of Wettest Quarter 160 (Bio8), Mean Temperature of Driest Quarter (Bio9), Precipitation Seasonality (Coefficient of 161 Variation) (Bio15), Precipitation of Coldest Quarter (Bio19) and Altitude (ALT).

162 Given the uncertainty in scenarios of future climate scenarios, impact assessments should 163 incorporate data from a range of climate models that effectively simulate historical climate over 164 the area of interest (Guisan et al., 2013). Therefore, to predict the future potential distribution of 165 CAS on a global scale, the Hadley Global Environment Model 2-Atmosphere Ocean 166 (HADGEM2-AO), Geophysical Fluid Dynamics Laboratory Coupled Model v3 (GFDL-CM3) 167 and Model for Interdisciplinary Research on Climate (MIROC5) for 2050 (average for 2041168 2060) and 2070 (average for 2061-2080) were obtained from the Coupled Model 169 Intercomparison Project Phase 5 (CMIP5) of the fifth assessment of the International Panel on 170 Climate Change (IPCC) in 2010 (Moss et al., 2010). Four possible greenhouse gas concentration 171 trajectories were selected that ranged from low (RCP 2.6) to high (RCP 8.5) and corresponded to 172 increases in global radiative forcing values in the year 2100 relative to preindustrial values (2.6, $1734.5,6.0$ and $8.5 \mathrm{w} / \mathrm{m}^{2}$, respectively). Additionally, it was assumed that the global mean 174 temperature will increase by $0.3^{\circ} \mathrm{C}$ to $4.8^{\circ} \mathrm{C}$ by 2100 across all RCPs (van Vuuren et al., 2011). 175 Four climate change scenario/year combinations were selected to simulate the future influence of 176 potentially extreme climatic variations on the geographical distribution patterns: RCP 2.6-2050, 177 RCP 8.5-2050, RCP 2.6- 2070 and RCP 8.5-2070. All future climate projection data were 
178 download from the WorldClim Database (http://www.worldclim.org). All current and future data

179 had a spatial resolution of 2.5 arc $\min$ (approx. $\sim 5 \mathrm{~km}$ resolution at the equator).

180 MaxEnt Modelling

181 In recent years, MaxEnt software (MaxEnt version 3.3.3k, $182 \mathrm{http}: / /$ www.cs.princeton.edu/ schapire/maxent/) has frequently been used to simulate shifts in 183 species ranges under current and future climate scenarios (Ponce-Reyes et al., 2012; Wong et al., 184 2013; Cooper et al., 2016). This software is popular because it requires only presence-only data. 185 Comparative studies have consistently shown that MaxEnt has excellent performance and 186 outperforms than many other methods (such as GARP) in estimating potential species 187 distributions, particularly when sample sizes are small (Elith et al., 2006; Bosso et al., 2016; 188 Sultana et al., 2017). Moreover, some studies found that this software performed well regardless 189 of the number or geographical extent of species records, compared to the performance of 190 mahalannobis typicalities, random forests methods and other methods (Bosso et al., 2016; 191 Hernandez et al., 2006; Elith et al., 2011).

192 Building models from MaxEnt with an appropriate amount of complexity for the study 193 objectives is critical for robust inference (Merow et al., 2014). Moreover, for several reasons, the 194 default settings of MaxEnt are expected to produce overfit models (Radosavijevic \& Anderson, 195 2014). Recent studies have demonstrated the importance of both balancing model complexity 196 and predictive power and evaluating model's performance with spatially independent data.

197 Hence, in order to produce the best possible model for CAS, avoiding overfitting while 198 maximizing predictive power, we employed the R package ENMeval to select the optimal 199 combination of two important MaxEnt's parameters, the value of the regularization multiplier 200 and the combination of feature classes (Muscarella et al., 2014; Warren \& Seifert, 2011). In this 201 study, the "checkerboard2" approach was used by calculating the standardized Akaike 202 nformation criterion coefficient (AICc), and the parameterizations that resulted in the model with 203 the lowest delta AICc score were selected to run the final MaxEnt models. The regularization 204 multiplier was varied from 0.5 to 4 in increments of 0.5 , and the following six feature 205 combinations were tested: (1) Linear (L); (2) Linear (L) and Quadratic (Q); (3) Hinge (H); (4) 206 Linear (L), Quadratic (Q) and Hinge (H); (5) Linear (L), Quadratic (Q), Hinge (H) and Product 207 (P); (6) Linear (L), Quadratic(Q), Hinge (H), Product (P) and Threshold (T). The ENMeval 208 package were implemented in R 3.1.3 (R core Team, 2015). The result were shown in Table S4 
209 and Figure S1. Thus, a regularization multiplier=2.5; feature combinations = Linear, Quadratic 210 and Hinge (LQH) were choose in final MaxEnt configuration. Background points were randomly

211 chosen within the area enclosed by a minimum convex polygon comprising all records of the 212 species of interest as suggested by Phillips (2008). The logistic output of MaxEnt was used for 213 all the analyses. The $10^{\text {th }}$ percentile training presence logistic threshold was used to define the 214 suitable and unsuitable habitats for CAS. This threshold is a conservative value that is widely 215 adopted in species distribution modelling, especially when data have been collected by different 216 observers and have been collected using different methods over a long time (Bosso et al., 2016).

217 By applying this threshold, binary presence/absence maps were created using the reclassify 218 module from ArcGIS 10.1 (ESRI, Redlands, CA, USA). To maximize the predictive information 219 and simplification of future analysis, the suitable habitat areas for CAS were reclassified into 220 four levels: unsuitable habitat (no risk), low habitat suitability (low risk), moderate habitat 221 suitability (medium risk) and high habitat suitability (high risk). The area under the curve 222 (AUC) of the receiver operating characteristic (ROC) (Fielding \& Bell, 1997) and the true skill 223 statistic (TSS; sensitivity+ specificity -1) (Allouche, Tsoar \& Kadmon, 2006) were used to 224 estimate the performance of the model according to Swets (1988). The AUC value ranges from $2250-1$, where a value below 0.5 can be interpreted as a random prediction; 0.5-0.7 indicates poor 226 model performance; 0.7-0.9 indicates moderate performance; and a value above 0.9 is

227

228

229 230

231

232

233

234

235

236

237

238 considered to have "good" discrimination abilities (Peterson et al., 2011). The TSS accounts for both omission and commission errors, and the value range from -1 to 1 , where 1 indicates perfect agreement and 0 represents a random fit. Excellent model performances are expressed by TSS values close to 1 (Allouche, Tsoar \& Kadmon, 2006).

A 10-fold cross-validation was used to run MaxEnt to prevent random errors from affecting the selection of the validation and prediction sample. To assess the influence of environmental variables on species, the jackknife test was used to measure the importance e and the percent contributions of each variable. To account for variation among GCMs, a final projection environmental suitability map was created for CAS by averaging the projections from the all future climate scenarios.

\section{RESULTS}

\section{Model performance for potential distribution}


The model performance for A. yasumatsui was better than random based on 10-fold cross

240

241

242

243

244

245

246

247

248

249

250

251

252

253

254

255

256

257

258

259

260

261

262

263

264

265

266

267

268

269 validation, with a mean AUC value of $0.939 \pm 0.02$ and a TSS value of $0.701 \pm 0.11$. A "maximum training sensitivity plus specificity" threshold value of 0.112 was obtained from the 10th percentile training presence of the species occurrences. The suitable habitat areas for the pest were reclassified into four levels: $<0.112$ which indicated unsuitable habitat (no risk); 0.112-0.4, which indicated low habitat suitability (low risk); 0.4-0.6, which indicated moderate habitat suitability (medium risk); and $>0.6$, which indicated high habitat suitability (high risk).

\section{Important environmental variables}

Among the six environmental variables, Mean Temperature of Driest Quarter (Bio9) and Altitude (Alt) had the largest contributions to the distribution model for A. yasumatsui (Table 1). These two factors could explain $74.8 \%$ of the modeled distribution. The contributions of the other factors, i.e., Precipitation of Coldest Quarter (Bio19), Mean Temperature of Wettest Quarter (Bio8), Mean Diurnal Range (Bio2) and Precipitation Seasonality (Coefficient of Variation) (Bio15) had contributions of the model were $15.2 \%, 6.8 \%, 2.7 \%$ and $0.5 \%$, respectively, to the model. It appeared thermal conditions and topography were more important than other variables in creating the distribution map for this pest.

\section{Current invasion pattern}

The current distribution pattern of A. yasumatsui based on the current environmental variables and occurrence records (including invasive records and native records) is shown in Fig.1. The current climatic variables in the invasive range of the pest, as predict from MaxEnt, were used to identify potential distribution areas around the world, which were especially concentrated in North America, South America, Europe and Asia. In the USA, Florida, Georgia, Alabama, Louisiana and Texas had high invasion risks under the current climate scenario and areas with moderate invasion probabilities were also found in eastern Mexico. In addition, the Hawaiian Islands were also identified as having high potential distribution areas on the current map. In Europe, moderate-risk areas included France and Italy. In Asia, India, South China, Malaysia, Vietnam and Japan as well as portions of eastern Laos and Indonesia were the areas with the highest risk on the current potential distribution map. In Africa, the potential distribution area will extend to the east of Africa. Based on current climatic variables, the total area of potential suitable habitat for this pest is approximately $46,432,375 \mathrm{~km}^{2}$, of which $2,390,775 \mathrm{~km}^{2}$

(i.e., $5.1 \%$ of the total potentially invadable area) has high habitat suitability (high risk), and 
$2705,557,900 \mathrm{~km}^{2}$ (approximately $11.9 \%$ of the total potentially invadable area) has moderate 271 habitat suitability (Table 2).

272 Based on the response curves (Fig. 2A-F), the climatic conditions associated with high 273 habitat suitability were $25-28^{\circ} \mathrm{C}$ for Bio8, $15-20^{\circ} \mathrm{C}$ for Bio9, 200-400 mm for Bio 19 . However, 274 both Bio2 and Bio15 shown no relation to high habitat suitability.

\section{Future invasion risk}

276 The MaxEnt models based on the RCP 2.6 emission scenarios for the potential distribution 277 of A. yasumatsui in 2050 are presented in Fig. 3A and Table 2. The potential area of invasion 278 with suitable habitat was $40,077,550 \mathrm{~km}^{2}$, which represents an shrink of $13.6 \%$ over the current 279 area of suitable habitat. The area of highly suitable habitat expand to 2,734,675 $\mathrm{km}^{2}$ (an increase 280 of approximately $14.3 \%$ over the current highly suitable area).

281 The potential area of distribution with all suitable habitat will be decrease, but area of 282 highly suitable habitat expand in some area during this period. In Asia (Fig. S2 and Table 2), the 283 model predicts that the amount of suitable habitat in this area will be $10,441,600 \mathrm{~km}^{2}$ based on 284 current climatic variables. Suitable conditions would expand under the RCP 2.6-2050 future 285 climate scenario (Fig. S2 and Table 2), but the areas with high potential invasive ranges were 286 mostly concentrated at low latitudes, where the species will continue to expand to an area of $1,350,900 \mathrm{~km}^{2}$ (an increase of approximately $88.9 \%$ over the current highly suitable area) under RCP 8.5-2050. Expansions in the total suitable area and highly suitable area also occurred in 289 Europe (Fig. S3 and Table 2). However, the suitable and highly suitable areas decreased in

290

291

292

293 294

295 296

297 298 299 Africa (Fig. S4 and Table 2) and in North America (Fig. S5 and Table 2) under these climatic scenarios.

Under the RCP 2.6-2070 future climate scenario, MaxEnt predicted a gain in the area of suitable habitat of 39,006,250 $\mathrm{km}^{2}$, approximately $15.9 \%$ decrease over the current status (Fig. 3B and Table 2). The highly suitable area might notable increase of by $17.1 \% \%$ under this scenario, expanding to $2,801,300 \mathrm{~km}^{2}$. The restricted range expansion of the suitable habitat area under this climatic scenario also occurred in Italy, the Kingdom of Bhutan, north-west Africa, northern Bangladesh, Southeast India, South China and some regions in Russia (Fig.3 and Table 2). Moreover, the expansions in the total and highly suitable areas also occurred in Europe (Fig. S3 and Table 2) and Asia (Fig. S2 and Table 2). However, the suitable and highly suitable areas decreased in Africa (Fig. S4 and Table 2) and in North America (Fig. S5 and Table 2) under 
301 these climatic scenarios. Under RCP 8.5-2050, the model-predicted area of suitable habitat was

$30238,217,200 \mathrm{~km}^{2}$, which represents an decrease of approximately $15.9 \%$ over the current suitable

303 habitat area (Fig. 3C and Table 2), and the highly suitable area expanded to 2,801,300 $\mathrm{km}^{2}$ (an

304 increase of $17.1 \%$ over the current extents). In this scenario, the potential highly potential

305 suitable area in Asia will be increase to 1,369,925 $\mathrm{km}^{2}$ (approximately $91.5 \%$ increase over the

306 current area) (Fig. S2 and Table 2) and 129,925 km² in Europe (approximately 41.4\% increase

307 over the current area) (Fig. S3 and Table 2). However, in Africa (Fig. S4 and Table 2) and North

308 America (Fig. S5 and Table 2), the highly suitable area will shrink to 54,625 km² (i.e., a decrease

309 of about $60 \%$ compared to the current extent) and $605,675 \mathrm{~km}^{2}$ (i.e., a decrease of about $1.5 \%$

310 compared to the current extent), respectively.

311 MaxEnt predicted that the area of suitable habitat under the RCP 8.5-2070 future climate 312 scenario would be $38,189,200 \mathrm{~km}^{2}$, which is actually an decrease approximately $17.7 \%$ over the 313 current area (Fig. 3D and Table 2), but the highly suitable area expanded to 2,859,175 $\mathrm{km}^{2}$ (a 314 19.5\% increase). In this scenario (Fig. S2 and Table 2), the potential highly suitable area in Asia 315 will continue to expand to $9,091,925 \mathrm{~km}^{2}$ (an increase of approximately $11.9 \%$ over the current 316 extent); in Africa (Fig. S4 and Table 2), the area will shrink to $37,800 \mathrm{~km}^{2}$ (a decrease of 317 approximately 72.3\%); and in Europe (Fig. S3 and Table 2), the area will expand to 141,775 $\mathrm{km}^{2}$ 318 (an increase of approximately 54\% over the current extent). However, the potential highly 319 suitable area in North America (Fig. S5 and Table 2) will further decrease to 501,250 km².

320 In short, the potential distribution of this pest will increase with climate change;

321 Specifically, the area of highly suitable habitat will increase in most areas, but decreases in both 322 the areas of suitable and highly suitable habitats will occur in Africa (Fig. S4 and Table 2) and 323 also in North America (Fig. S5 and Table 2) under the future climatic scenario.

\section{DISCUSSION}

\section{Change in habitat suitability}

326 In this paper, the potential distribution of the invasive CAS was first simulated using 327 MaxEnt and presence data. The CAS is native to Thailand and has already invaded other continents. The results of the simulation of the potential distribution of this invasive scale insect showed that climate change would affect its worldwide distribution. Our model also suggests that the CAS has a high invasive potential and is capable of invading large portions of the global landmass on several continents, particularly in South China, North India, north-western Africa 
332 and some areas of Russia. The occurrence of unsuitable areas on the current distribution map of 333 A. yasumatsui suggests that these areas are constrained by inappropriate ecological conditions

334 due to natural enemies or local adaptation, but these areas are expected to change over time with 335 the increase in climate warming. This pest is already causing serious damage to the mature 336 leaves and trunks of many cycad species (Normark, 2017) in Southern China, Guam, and 337 Florida, where the pest is invasive. Interestingly, our results suggests that western Australia, 338 northern New Zealand, western Madagascar, southern Brazil, Uruguay and northeastern 339 Argentina have suitable habitat for this pest; however, fortunately, there have not been any 340 reports of its presence at these sites. Thus, strict quarantine measures should be enforced across 341 these regions to prohibit the spread of this pest from its invasive and native ranges. The potential 342 distribution map for this pest provides a reference for developing monitoring strategies to detect 343 future infestations in currently uninfected regions.

344 However, not all regions showed an expansion of the potential distribution range under 345 climate change. Based on two climate scenarios, the current research showed that climate change 346 will reduce the risk of invasion on some continents, such as Africa and previous studies have 347 also suggested that some invasive species are likely to experience range reductions due to 348 climate change (Sarma, Munsi \& Ananthram, 2015; Bardley et al., 2010; Roura-pascual et al., 349 2004). Retreat by invasive pests could lead to opportunities for the restoration of currently 350 invaded landscapes, but further research is needed to identify these opportunities and provide 351 sound guidance for ecological restoration.

\section{Factors influencing invasion}

353 The results of the potential CAS distribution modelling by MaxEnt showed that the Mean 354 Temperature of Driest Quarter is the most important climatic variable defining the current global 355 distribution of this pest. Previous results have demonstrated that CAS eggs hatch to nymphs in 835612 days when the temperature is $24.5^{\circ} \mathrm{C}$ (Howard et al., 1999) and adult female would be not laid 357 eggs when temperature at $18^{\circ} \mathrm{C}$ and $35^{\circ} \mathrm{C}$ (Cave et al., 2009). Moreover, $25^{\circ} \mathrm{C}-28^{\circ} \mathrm{C}$ has been 358 confirmed to be the most suitable temperature range for the development and reproduction of 359 CAS (Ravuiwasa et al., 2012). However, temperatures below $15^{\circ} \mathrm{C}$ have been shown to be 360 unsuitable for this insect, as indicated by the high mortality observed in laboratory research 361 (Teaaro, 2009). Moreover, some research has suggested there were significant correlations 362 between population growth and temperature variations. Our results confirmed that the mean 
363 temperature of driest quarter is the most important factor affecting the model, accounting for $36448.1 \%$ of the contribution of all climatic variables. Our model suggested that the population of 365 this pest would increase under an mean temperature of $15-20^{\circ} \mathrm{C}$ in the driest quarter and a mean 366 temperature of $25-28^{\circ} \mathrm{C}$ in the wettest quarter. Therefore, these temperature values represent the 367 most suitable climatic conditions for the population growth of this pest and some currently 368 unsuitable habitats, such as southern China, may be come suitable in the future as currently 369 suitable areas become too hot for CAS development. In contrast, some currently highly suitable 370 habitats, such as North America, may become unsuitable due to global warming. This decrease 371 in habitat suitability in these regions may constraint the spread of CAS outside its current 372 suitable range or limit its development.

373 Although the potential distribution of CAS under climate change was predicted by MaxEnt, 374 other factors may have limited the accuracy of our results. Only constraints caused by climate 375 conditions were considered in the current research; however, other factors, such as host-plant 376 availability (Ning, Wei \& Feng, 2017), interspecific interactions (Gao \& Reitz, 2017), and 377 dispersal ability (Guisan \& Thuller, 2005), also affected the precision of the model; these factors 378 should considered in future research.

\section{Implications for management strategies}

380 Reasonable management strategies and effective control methods are the key to controlling

381

382

383

384

385

386

387

388

389

390

391

392

393 the spread of CAS and they should be based on a broad consideration of the relationship between invasive species and other factors such as climate change, land use, and human activities (Pyke et al., 2008). Based on the results of the current and past studies, one possible method and management strategy for controlling this species is proposed here.

First, identifying the areas experiencing climate change is a critical step (Pyke et al., 2008). Species distribution modeling (SDM) is a cost-effective, simply early warning system that enables the identification of potential invasion areas (Warren, 2012). Forecasting future areas of invasion by SDM provides an opportunity for governments to prioritize those regions for management and then develop strategies to control pests in these areas. For example, our results suggest that CAS has a highly suitable environment in southern China, which has severely harmed Cycas revoluta in Shenzhen City of Guangdong Province (Yang et al., 2009) and Cycas guizhouensis in Guizhou Province ( $W u, L i \&$ \&uo, 2008); however, unfortunately, no management strategy for controlling this pest is exists in these region. Moreover, some regions, 
394 such as western Australia, northern New Zealand, western Madagascar, southern Brazil,

395 Uruguay and north-eastern Argentina, were identified as having suitable habitat for the CAS in 396 our work. Therefore, these areas should formulate strict quarantine measures to prevent invasion 397 by this pest.

398 Second, many studies have shown that the use of oil (organocide or paraffin-based ultra-fine 399 horticultural oils) on foliage can significantly reduce CAS population size, but several 400 applications may be required (Hodges, Howard \& Buss, 2003). Conventional insecticides, such 401 as cygon and pyriproxifen (Weissling, Howard \& Hamon, 1999; Emshousen, Mannion \& Glenn, 402 2004; Howard et al., 1999), can also control CAS in some instance. However, the chemical 403 control efficiency is low, because the scale can protect itself by hiding between the leaves or 404 stems of cycads (Hodges et al., 2003). Therefore, a combination of biological control agents and 405 chemical control can improve management efforts.

406 Finally, natural enemies are likely another effective way to control CAS. The first 407 biological control agents, a parasitic wasp, Coccobius fulvus and a predatory beetle, 408 Cybocephalus nipponicus, were released in 1998 (Cave, 2006), but a satisfactory level of control 409 has not been achieved. Since then, many natural enemies have been used to control CAS at 410 certain times and over certain ranges; for example, both Cybocephalus nipponicus and $C$. 411 flavocapitis are effective biological control agents of CAS in Taiwan Province, China (Bailey et 412 al., 2011). Approximately 15,000 Coccobius fulvus individuals were released in 14 Florida 413 counties during February-April 2002, and good CAS control results were observed (Cave, 2006). 414 Moreover, some new natural enemies have been found to feed on CAS, but their control efficacy 415 needs to be further verified. These biological control agents included Rhyzobius lophanthae, 416 Aphytis lingnanensis and Aphytis lepidosaphes.

417 In brief, areas that have been invaded by CAS must combine chemical control with natural 418 predators to manage this pest. Additionally, strict quarantine measures should be implemented in 419 areas where this pest has not yet been recorded but where climatic conditions appear to be 420 suitable to CAS, as suggested by our results.

\section{CONCLUSIONS}

422 Invasive species are considered a major threat to ecosystem functioning and native 423 biodiversity. Climate changes can enhance invasion processes from initial introduction through 424 establishment and spread, and consequently have a profound influence on agricultural systems. 
425 The CAS is one of the most serious pests of cycads that has emerged in recent years. This study 426 provided the first potential distribution map based on current and future climate scenarios, and 427 the result showed that the potentially suitable habitat area or CAS is far greater than the current 428 distribution under current climate conditions. The amount of suitable habitats will continue to 429 increase under future climate change scenarios. The present study only provides a reference to 430 the manage this invasive species and develop policies for its control; thus, further research is 431 required.

432 REFERENCES

433 Allouche O, Tsoar A, Kadmon R. 2006. Assessing the accuracy of species distribution models: 434 prevalence, kappa and the true skill statistic (TSS). Journal of Applied Ecology 43(6): 1223$435 \quad 1232$

436 Bailey R, Chang NT, Lai PY. 2011. Two-sex life table and predation rate of Cybocephalus 437 438 flavocapitis Smith (Coleoptera: Cybocephalidae) spread on Aulacaspis yasumatsui Takagi (Hemiptera: Diaspididae) in Taiwan. Journal of Asia-pacific Entomolgoy 14(4): 433-439

Bellard C, Thuiller W, Leroy B, Genovesi P, Bakkenes M, Courchamp F. 2013. Will climate change promote future invasions? Global Change Biology 19(12): 3740-3748

Bosso L, Febbraro MD, Cristinzio G, Zoina A, Russo D. 2016. Shedding light on the effects of climate change on the potential distribution of Xylella fastidiosa in the Mediterranean basin. Biology Invasions 18(6): 1759-1768

444

Bradley BA, Wilcove DS, Oppenheimer M. 2000. Climate change increases risk of plant 445 invasion in the Eastern United States. Biology Invasions 12(6): 1855-1872.

Bradley BA, Blumenthal DM, Wilcove DS, Ziska LH. 2010. Predicting plant invasions in an era of global change. Trend in Ecology and Evolution 25(5): 310-318

Brenner ED, Stevenson DW, Twigg RW. 2003. Cycads: evolutionary innovations and the role of plant-derived neurotoxins. Trends in Plant Science 8(9): 446-452

450

451

452

453

454

Cave RD. 2006. Biological control agents of the cycad Aulacaspis scale, Aulacaspis yasumatsui. Proceedings of the Florida State Horticultural Society 119: 422-424

Cave RD, Sciacchetano C, Diaz R. 2009. Temperature-Dependent development of the Cycad Aulacaspis scale, Aulacaspis yasumatsui (Hemiptera: Diaspididae). Florida Entomological Society 92(4): 578-581. 
455

456

457

458

459

460

461

462

463

464

465

466

467

468

469

470

471

472

473

474

475

476

477

478

479

480

481

482

483

484

485

486

Cooper DM, Dugmore AJ, Gittings BM, Scharf AK, Wilting A, Kitchener AC. 2016. Predited Pleistocene-Holocene range shifts of the tiger (Panthera tigris). Diversity and Distribution 22: 1199-1211.

Duan JJ, David EJ, Dontay C, Williams D, Kristi ML. 2014. Patterns of parasitoid host utilization and development across a range of temperatures: implications for biological control of an invasive forest pest. BioControl 59 (6): 659-669

Ekesi S, Meyer MD, Mohamed SA, Virgilio M, Borgemeister C. 2016. Taxonomy, ecology, and management of native and exotic fruit fly species in Africa. Annual review of entomology 61(1): 219-238.

Elith J, Graham CH, Anderson RP, Dudik M, Ferrier S, Guisan A, Hijmans RJ, Huettmann F, Leathwick JR, Lehmann A, Li J, Lohmann LG, Loiselle BA, Manion G, Moritz C, Nakamura M, Nakazawa Y, McC J, Peterson AT, Phillips SJ, Richardson K, Scachetti-Pereira R, Schapire RE, Soberon J, Williams S, Wisz MS, Zimmermann NE. 2006. Novel methods improve prediction of species' distributions from occurrence data. Ecography 29:129-151.

Elith J, Phillips SJ, Hastie T, Dudík M, Chee YE, Yates CJ. 2011. A statistical explanation of MaxEnt for ecologists. Diversity and Distributions 17(1): 43-57.

Emshousen C, Mannion C, Glenn H. 2004. Management of cycad Aulacaspis scale, Aulacaspis yasumatsui Takagi. Proceedings of the Florida State Horticultural Society 117: 305-307.

EPPO. 2017. EPPO Global Database. Available online at: https://gd.eppo.int.

Fielding AH, Bell JF. 1997. A review of methods for the assessment of prediction errors in conservation presence/absence models. Environmental conservation 24: 38-49

García M, Denno B, Miller DR, Miller GL, Ben-Dov Y, Hardy NB. 2017. ScaleNet:A Literature-based model of scale insect biology and systematics. Available at http://scalenet.info [accessed: 2017].

Gao YL, Reitz SR. 2017. Emerging themes in our understanding of species displacements. Annual review of entomology 62: 165-183

Germain JF. 2002. Scale insects (homoptera: Coccoidea) from import interception in France (1997-2001). Bollettino di Zoologia Agraria di Bachicoltura (Milano) 33(3):504

Giorgi JA, Vandenberg NJ. 2012. Review of the lady beetle genus Phaenochilus Weise (Coleoptera: Coccinellidae: Chilocorini) with description a new species from Thailand that 
487

488

489

490

491

492

493

494

495

496

497

498

499

500

501

502

503

504

505

506

507

508

509

510

511

512

513

514

515

516

517

preys on cycad aulacaspis scale, Aulacaspis yasumatsui Takagi (Hemiptera: Sternorrhyncha: Diaspididae). Zootaxa 3748: 239-255

González-Gómez R, Riverón-Giró FB, García-González A, Martinez-Rosas R, SolísMontero L. 2016. First report of Aulacaspis yasumatsui (Hemiptera: Diaspidida) in Mexico. Florida Entomologist 99(3): 583-584

Guisan A, Tingley R, Baumgartner JB, Naujokaitis-Lewis I, Sutcliffe PR, Tulloch AIT, Regan TJ, Brotons L, McDonald-Madden E, Mantyka-Pringle C, Martin TG, Rhodes JR, Maggini R, Setterfield SA, Elith J, Schwartz MW, Wintle BA, Broennimann O, Asutin M, Ferrier S, Kearney MR, Possingham HP, Buckley YM. 2013. Predicting species distributions for conservation decisions. Ecology letters 16(12): 1424-1435

Guisan A, Thuiller W. 2005. Predicting species distribution: offering more than simple habitat models. Ecology letters 8(9): 993-1009

Gullan PJ, Kosztarab M. 1997. Adaptations in scale insects. Annual reviews of entomology 42: 23-50.

Haynes J. 2005. Cycad aulacaspis scale: A global perspective. Cycad Newsletter 28: 3-6

Heikkinen RK, Luoto M, Araújo MB, Virkkala R, Thuiller W, Sykes MT. 2006. Methods and uncertainties in bioclimatic envelop modeling under climate change. Progress in physical geography 30: 1-27

Hernandez PA, Graham CH, Master LL, Albert DL. 2006. The effect of sample size and species characteristics on performance of different species distribution modeling methods. Ecography 5: 773-785.

Hijmans RJ, Cameron SE, Parra JL, Jones PG, Jarvis A. 2005. Very high resolution interpolated climate surfaces for global land areas. International journal of Climatology 25(15): 195-204

Hodgson C, Martin JH. 2001. Three noteworthy scale insects (Hemiptera: Coccoidea) from Hongkong and Singapore, including Cribropulvinaria tailungensis, new genus and species (Coccidae), and the status of the cycad-feeding Aulacaspis yasumatsui (Diaspididae). Raffles bulletin of zoology 49: 227-250

Hodges G, Howard FW, Buss EA. 2003. Update on management methods for cycad aulacaspis scale. Department of Agriculture and consumer services-entomology section (ENY-680) http://citeseerx.ist.psu.edu/viewdoc/download? 
518 Howard FW, Hamon A, Mclaughlin M, Weissling T, Yang SL. 1999. Aulacaspis yasumatsui

519 (Hemiptera: Sternorryncha: Diaspididae). A scale insect pest of cycads recently introduced

520 in to Floria. The Florida Entomologist 82(1): 14-26

521 Jiménez-Valverde A, Peterson AT, Soberón J, Overton JM, Argon P, Iobo JM. 2011. Use of

522 niche models in invasive species risk assessments. Biology invasions 13(2): 2785-2797.

523 Kadmon R, Farber O, Danin A. 2004. Effect of roadside bias on the accuracy of predictive 524 maps produced by bioclimatic models. Ecological applications 14 (2): 401-413.

525 Li GQ, Du S, Guo K. 2015. Evaluation of limiting climatic factors and simulation of a 526 climatically suitable habitat for Chinese sea buckthorn. Plos One 10(7): e0131659.

527 Luoto M, Virkkala R, Heikkinen RK. 2007. The role of land cover in bioclimatic models 528 depends on spatial resolution. Global ecology and biogeography 16:34-42.

529 Malumphy C, Marquart C. 2012. Queen sago palm (Cycas circinalis L.) killed by Asian Cycal 530 scale Aulacaspis yasumatsui Takagi (Hemiptera: Diaspididae) in Britain. Entomologist's 531 Monthly Magazine 148: 147-154.

532 Marler TE, Moore A. 2010. Cryptic scale infestations on Cycas revolute Facilitate scale 533 invasions. Hortscience 45(5): 837-839.

534 Marler TE, Lawrence JH. 2012. Demography of Cycas micronesica on Guam following 535 introduction of the armoured scale Aulacaspis yasumatsui. Journal of Tropical ecology 28: $536 \quad 233-242$.

537 Massin MB, Rome Q, Muller F, Perrard A, Villemant C, Jiguet F. 2012. Climate change 538 increases the risk of invasion by the yellow-legged hornet. Biological conservation 157: 453910.

540

541

542

Merow C, Smith MJ, Edwards Jr TC, Guisan A, McMahon SM, Normand S, Thuiler W, Wuest RO, Zimmermann NE, Elith J. 2014. What do we gain from simplicity verus complexity in species distribution models? Ecography 37: 1267-1281.

Medley KA. 2010. Niche shifts during the global invasion of the Asian tiger mosquito, Aedes 545 albopictus Skuse (Culicidae), revealed by reciprocal distribution models. Global ecology and biogeography 19: 122-133.

547

Milek TM, Šimala M, Novak A. 2008. Species of genus Aulacaspis Cockerell, 1836 548 (Hemiptera: Coccoidea: Diaspididae) in Croatia, with emphasis on Aulacaspis yasumatsui Takagi, 1977. Entomologia Croatica 12(1): 55-64. 
549

550

551

552

553

554

555

556

557

558

559

560

561

562

563

564

565

566

567

568

569

570

571

572

573

574

575

576

577

578

Moss RH, Edmond JA, Hibbard KA, Manning MR, Rose SK, van Vuuren DP, Carter TR, Emori S, Kainuma M, Kram T, Meehl GA, Mitchell JFB, Nakicenovic N, Riahi K, Smith SJ, Stouffer RJ, Thomson AM, Weyant JP, Wilbanks TJ. 2010. The next generation of scenarios fro climate change research and assessment. Nature 463 (7282): 747-756.

Muniappan R, Watson GW, Evans GA, Rauf A, Ellenrieder NV. 2012. Cycad Aulacaspis scale, a newly introduced insect pest in Indonesia. Journal of Biosciences 19(3): 110-114.

Muscarella R, Galante PJ, Soley-Guardia M, Boria RA, Kass JM, Uriarte M, Anderson RP. 2014. ENMeval: An R package for conducting spatially independent evaluations and estimating optimal model complexity for MaxEnt ecological niche models. Methods in ecology and evolution 5(11): 1198-1205.

Nesamari R, Millar IM, Coutinho TA, Roux J. 2015. South African cycads at risk: Aulacaspis yasumatsui (Hemiptera: Coccoidea: Diaspididae) in South Africa. Africa entomology 12 (1): 196-206.

Ning SY, Wei JF, Feng JN. 2017. Predicting the current potential and future worldwide distribution of the onion maggot, Delia antique using maximum entropy ecological niche modeling. PLOS ONE 12(2): e0171190.

Normark BB, Normark RD, Vovides A, Lislie Solis-Montero L, Gonzalez-Gomez R, Pulido-Silva MT, Escobar-Castellanos MA, Dominguez M, Perez-Farrera MA, Janda M, Cibrian-Jaramillo A. 2017. Cycad aulacaspis scale (Aulacaspis yasumatsui Takagi, 1977) in Mexico and Guatemala: a threat to native cycads. BioInvasions Records 6(3): 187193.

Paini DR, Sheppard AW, Cook DC, Barro PJD, Worner SP, Thomas MB. 2016. Global threat to agriculture from invasive species.Proceedings of the national academy of sciences of the united states of America 113 (27): 7575-7579.

Peterson AT, Soberón RG, Pearson RP, Anderson E, Martinez-Meyer M, Nakamura, Araujo MB. 2011. Ecological Niches and Geographic Distributions. Princeton University Press, Princeton, New Jersey, USA.

Phillips SJ. 2008. Transferabiligy, sample selection bias and background data in presence-only modeling: a response to Peterson et al. (2007). Ecography 31: 272-278 
579

580

581

582

583

584

585

586

587

588

589

590

591

592

593

594

595

596

597

598

599

600

601

602

603

604

605

606

607

608

609

610

Ponce-Reyes R, Reynoso-Rosales VH, Watson JEM, VanDerWal J, Fuller RA, Pressey RL, Possingham HP. 2012. Vulnerability of cloud forest reserves in Mexico to climate change. Nature climate change 2, 448-452.

Pyke CR, Thomas R, Porter RD, Hellmann JJ, Dukes JS, Lodge DM, Chavarria G. 2008. Current practices and future opportunities for policy on climate change and invasive species. Conservation biology 22(3): 585-592.

Radosavijevic A, Anderson RP. 2014. Making better Maxent models of species distributions: complexity, overfitting and evaluation. Journal of Biogeography 41: 629-643.

Ravuiwasa KT, Tan CW, Bezirganoglu I, Hwang SY. 2012. Temperature-dependent demography of Aulacaspis yasumatsui (Hemiptera: Diaspididae). Journal of Economic Entomology 105(5): 1581-1590.

R core Team. 2015. R: A language and environment for statistical computing (R Foundation for StatisticalComputing, Vienna). http://www.R-project.org/

Rodriguez-Castaneda G, Hof RA, Jansson R, Harding LE. 2012. Predicting the fate of Biodiversity using species' distribution models: Enhancing model comparabiligy and repeatability. PLOS ONE 7(9): e44402.

Root TL, Price JT, Hall KR. 2003. Schneider SH. Fingerprints of global warming on wild animals and plants. Nature 421: 57-60.

Roura-pascual N, Suarez AV, Gomez C, Pons P, Touyama Y, Wild AL, Peterson AT. 2004. Geographical potential of Argentine ants (Linepithema humile Mayr) in the face of global climate change. Proceedings of the Royal Society, B 271: 2527-2534.

Salas-Leiva DE, Meerow AW, Calonje M, Griffith MP, Francisco-Ortega J, Nakamura K, Stevenson DW, Lewis CE, Namoff S. 2013. Phylogeny of cycads based on multiple single-copy nuclear genes: congruence of concatenated parsimony, likelihood and species tree inference methods. Annals of Botany 112: 1263-1278.

Sarma RR, Munsi M, Ananthram AN. 2015. Effect of Climate Change on Invasion Risk of Giant African Snail (Achatina fulica Férussac, 1821: Achatinidae) in India. PLoS ONE 10(11): e0143724.

Simberloff D, Martin JL, Genovesi P, Maris V, Wardle DA, Aronson J, Courchamp F, Galil B, Garcia-Berthou E, Pascal M, Pysek P, Sousa R, Tabacchi E, Vila M. 2003. Impacts of biological invasions: what's what and the way forward. Trends in Ecology and Evolution 28: 58-66. 
611 Sultana S, Baumgartner JB, Dominiak BC, Royer JE, Beaumont LJ. 2017. Potential impacts

612 of climate change on habitat suitability for the Queensland fruit fly. Scientific reports 7: $613 \quad 13025$.

614 Swets JA. 1988.Measuring the accuracy of diagnostic systems. Science 240: 1258-1293

615 Takagi S. 1977. A new species of Aulacaspis associated with a cycad in Thailand (Homoptera:

616 Coccoidea). Insecta Matsumurana New Series 11: 63-72.

617 Takagi S, De faveri S. 2009. Notes on scale insects of Aulacaspis associated with mangroves 618 and cycads (Sternorrhyncha: Coccoidea: Diaspididae). Insecta matsumurana, Series 619 entomology. New series 65: 101-129.

620 Tang W, Yang SL, Vatcharakorn P. 1997. Cycads of Thailand. Nong Nooch Tropical Garden 621 and Cycad conservation company, Bangkok, Thailand.

622 Teaaro O. 2009. Life history of cycad aulacaspis scale, Aulacaspis yasumatsui Takagi, at 623 different temperatures. Dissertation of Department of tropical agriculture and international 624 cooperation, Pingtung University.

625 Terry I, Marler T. 2005. Paradise lost? Tipping the scales against Guam's Cycas micronesica. 626 The Cycad Newsletter 28: 21-23

627 van Vuuren DP, Edmonds J, Kainuma M, Riahi K, Thomson A, Hibbard K, Hurtt GC, 628 Kram T, Krey V, Lamarque JF, Masui T, Meinshausen M, Nakicenovic N, Smith SJ, 629 630 Rose SK. 2011. The representative concentration pathways: an overview. Climatic change 109 (1): 5-31

632

633

634

Walsh JR, Carpenter SR, Zanden MJV. 2016. Invasive species triggers a massive loss of ecosystem services through a trophic cascade. Proceedings of the national academy of sciences of the united states of America 113(115): 4081-4085.

635

636

637

638

639

Walters T, Shroyer E, Anderson L. 1997. Scale and south Florida Cycad. The Cycad Newsletter 20(1).

Warren DL. 2012. In defense of "niche modeling". Trends in ecology and evolution 27(9): 497-500.

Warren DL, Seifert SN. 2011. Ecological niche modeling in Maxent: the importance of model complexity and the performance of model selection criteria. Ecology Application 21: 335640 342. 
641 Weissling TJ, Howard FW, Hamon AB. 1999. Cycad aulacaspis scale, Aulacaspis yasumatsui 642 Takagi (Insecta: Homoptera: Sternorrhyncha: Diaspididae). Florida coop.ext. service 643 publication document EENY-096.July.

644 Wu YK, Li XH, Luo ZQ. 2008. Occurrence and control the Aulacaspis yasumatsui in Guizhou 645 Province. Plant Doctor 21 (2): 27-28.

646 Wu LW, Yen SH, Lees DC, Hsu YF. 2010. Elucidating genetic signatures of native and 647

648

649 introduced populations of the Cycad Bule, Chilades pandava to Taiwan: a threat both to

650 sago palm and to native cycas populations worldwide. Biological invasions 12(8): 26492669.

Wong MHG, Li RQ, Xu M, Long YC. 2013. An integrative approach to assessing the potential 651 impacts of climate change on the Yunnan snub-nosed monkey. Biological Conservation

652 158: $401-409$.

653 Yang WX, Wu WD, Jiao GL, Liu F. 2009. Biology of Aulacaspis yasumatsui Takagi and its 654 control test. Journal of Fujian Forestry Science and Technology 36(4): 127-129

655 Yousuf F, Carnegie AJ, Bedding RA, Bashford R, Nicol HI, Gurr GM. 2014. Effect of 656 temperature on wood-wasp (Sirex noctilio F.) development and parasitism by the entomopathogenic nematode, Deladenus siricidicola. Biological control 79: 62-74.

658

659 
Table $\mathbf{1}$ (on next page)

ENMeval results for CAS from SDMs 
1 Table 1 Relative contribution of each environmental variables to MaxEnt model.

\begin{tabular}{cc}
\hline Environment variables & Relative contribution \\
\hline Mean Temperature of Driest Quarter (Bio9) & $48.1 \%$ \\
Altitude (alt) & $26.7 \%$ \\
Precipitation of Coldest Quarter (Bio19) & $15.2 \%$ \\
Mean Temperature of Wettest Quarter (Bio8) & $6.8 \%$ \\
Mean Diurnal Range (Bio2) & $2.7 \%$ \\
Precipitation Seasonality (Coefficient of Variation) (Bio15) & $0.5 \%$ \\
\hline
\end{tabular}


Table 2 (on next page)

Relative contribution of each environmental variables to MaxEnt model 
Table 2. Area with suitability under different climate scenarios

\begin{tabular}{|c|c|c|c|c|c|c|}
\hline Range & Level & Current $\left(\mathrm{Km}^{2}\right)$ & RCP2.6-2050 $\left(\mathrm{Km}^{2}\right)$ & $\mathrm{RCP} 8.5-2050\left(\mathrm{Km}^{2}\right)$ & $\mathrm{RCP} 2.6-2070\left(\mathrm{Km}^{2}\right)$ & $\mathrm{RCP} 8.5-2070\left(\mathrm{Km}^{2}\right)$ \\
\hline \multirow{5}{*}{ Global } & $0.112-0.4$ & $38,483,700$ & $32,007,300(-16.8 \%)$ & $\begin{array}{c}30,260,450(- \\
21.3 \%)\end{array}$ & $\begin{array}{c}30,956,000(- \\
19.5 \%)\end{array}$ & $30,400,550(-21 \%)$ \\
\hline & $0.4-0.6$ & $5,557,900$ & $5,335,575(-4 \%)$ & $5,136,400(-7.5 \%)$ & $5,247,825(-5.5 \%)$ & $4,929,475(-11.3 \%)$ \\
\hline & 0.6-1 & $2,390,775$ & $2,734,675(14.3 \%)$ & $2,820,350(17.9 \%)$ & $2,801,300(17.1 \%)$ & $2,859,175(19.5 \%)$ \\
\hline & $\begin{array}{l}0.112-1 \text { (in } \\
\text { total) }\end{array}$ & $46,432,375$ & $40,077,550(-13.6 \%)$ & $\begin{array}{c}38,217,200(- \\
17.6 \%)\end{array}$ & $\begin{array}{c}39,006,250(- \\
15.9 \%)\end{array}$ & $38,189,200(-17.7 \%)$ \\
\hline & $0.112-0.4$ & $4,148,625$ & $6,346,125(53.9 \%)$ & $6,824,375(64.4 \%)$ & $5,927,825(42.8 \%)$ & $8,447,450(103 \%)$ \\
\hline \multirow[t]{2}{*}{ Europe } & $0.4-0.6$ & 398,425 & $912,600(129 \%)$ & $982,050(146 \%)$ & $932,150(133 \%)$ & $883,600(121 \%)$ \\
\hline & 0.6-1 & 91,850 & $121,550(32.3 \%)$ & $129,925(41.4 \%)$ & $161,150(75.4 \%)$ & $141,775(54 \%)$ \\
\hline \multirow{5}{*}{ Asia } & $\begin{array}{l}0.112-1 \text { (in } \\
\text { total) }\end{array}$ & $4,638,900$ & $7,380,275(59.0 \%)$ & $7,936,350(71.0 \%)$ & $7,021,125(51.3 \%)$ & $9,472,825(104 \%)$ \\
\hline & $0.112-0.4$ & $7,659,250$ & $7,112,625(-7.1 \%)$ & $6,267,600(-18.1 \%)$ & $7,195,725(-6 \%)$ & $5,487,525(-28.3 \%)$ \\
\hline & $0.4-0.6$ & $1,953,725$ & $1,978,075(1.2 \%)$ & $2,015,450(3.1 \%)$ & $1,979,800(1.3 \%)$ & $2,104,150(7.6 \%)$ \\
\hline & 0.6-1 & 715,000 & $1,350,900(88.9 \%)$ & $1,369,925(91.5 \%)$ & $1,316,900(84.1 \%)$ & $1,500,250(109 \%)$ \\
\hline & $\begin{array}{l}0.112-1 \text { (in } \\
\text { total) }\end{array}$ & $10,327,975$ & $10,441,600(1.1 \%)$ & $9,652,975(-6.5 \%)$ & $10,492,425(1.5 \%)$ & $9,091,925(11.9 \%)$ \\
\hline \multirow{4}{*}{$\begin{array}{l}\text { North } \\
\text { America }\end{array}$} & $0.112-0.4$ & $2,942,525$ & $3,351,250(13.8 \%)$ & $3,581,975(21.7 \%)$ & $3,241,450(10.1 \%)$ & $4,309,500(46.4 \%)$ \\
\hline & $0.4-0.6$ & 553,475 & $503,525(-9 \%)$ & $462,750(-16.3 \%)$ & $471,000(14.9 \%)$ & $509,700(-7.9 \%)$ \\
\hline & 0.6-1 & 615,325 & $550,250(-10.5 \%)$ & $605,675(-1.5 \%)$ & $638,900(3.8 \%)$ & $501,250(-18.5 \%)$ \\
\hline & $\begin{array}{l}0.112-1 \text { (in } \\
\text { total) }\end{array}$ & $4,111,325$ & $4,405,025(7.1 \%)$ & $4,900,400(19.1 \%)$ & $4,351,350(5.8 \%)$ & $5,320,450(29.4 \%)$ \\
\hline \multirow{4}{*}{ Africa } & $0.112-0.4$ & $6,374,350$ & $3,309,550(-48 \%)$ & $2,660,050(-58.2 \%)$ & $3,217,575(-49.5 \%)$ & $1,938,925(-69.5 \%)$ \\
\hline & $0.4-0.6$ & 415,775 & $281,375(-32.3 \%)$ & $250,625(-39.7 \%)$ & $281,350(-32.3 \%)$ & $171,700(-58.7 \%)$ \\
\hline & 0.6-1 & 136,800 & $77,475(-43.3 \%)$ & $54,625(-60.0 \%)$ & $74,700(-45.3 \%)$ & $37,800(-72.3 \%)$ \\
\hline & $\begin{array}{l}0.112-1 \text { (in } \\
\text { total) }\end{array}$ & $6,926,925$ & $3,668,400(-47 \%)$ & $2,965,300(-57.1 \%)$ & $3,573,625(-48.4 \%)$ & $2,148,425(-68.9 \%)$ \\
\hline
\end{tabular}




\section{Figure 1}

Native and invasive localities of CAS used in current modeling.

Red dot represent native localities and green dot represent invasive localities. The base map was created with Natural Earth Dataset (http://www.naturalearthdata.com/). Gray = unsuitable habitat area; Blue = low habitat suitability area; Green = moderate habitat suitability area; Red = highly habitat suitability area.

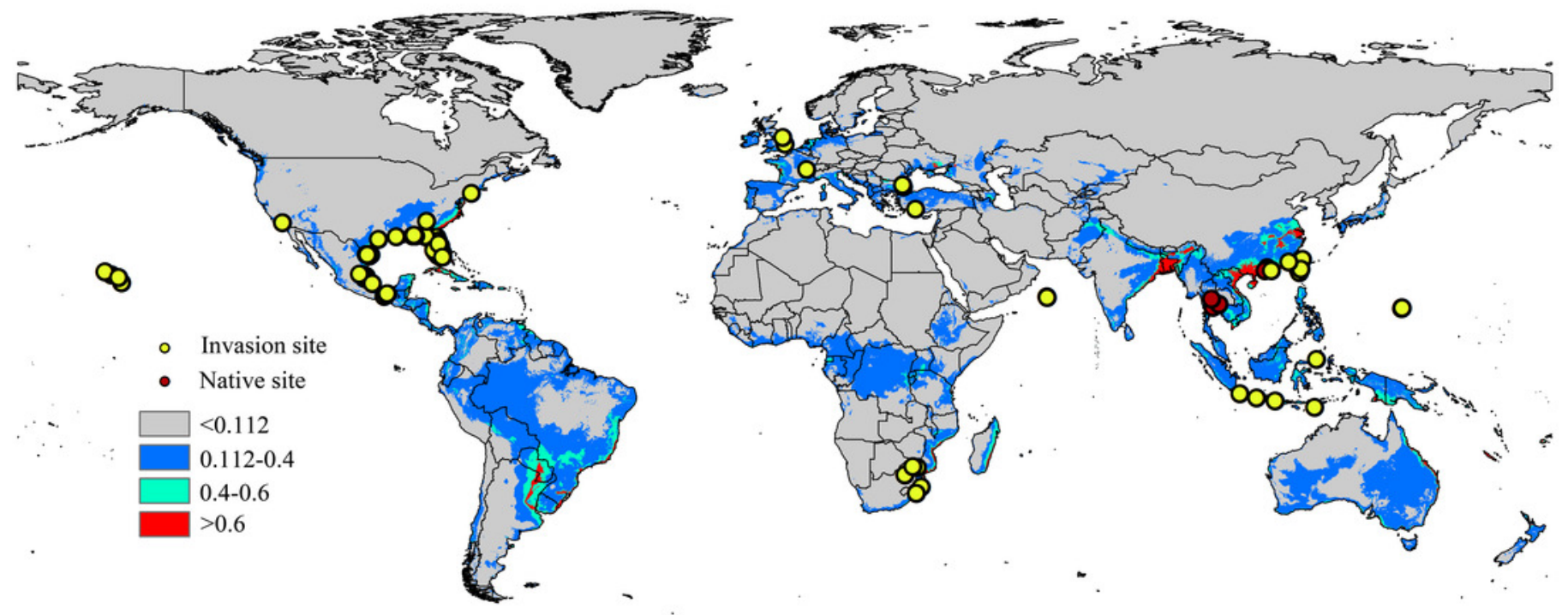


Figure 2

Response curves showing the relationships between the probability of presence of CAS and six bioclimatic variables

Values shown are average over 10 replicate runs: blue margins show \pm SD calculated over 10 replicates. $A=A l t ; B=B i 02 ; C=B i 08 ; D=B i 09 ; E=B i o 15 ; F=B i o 19$
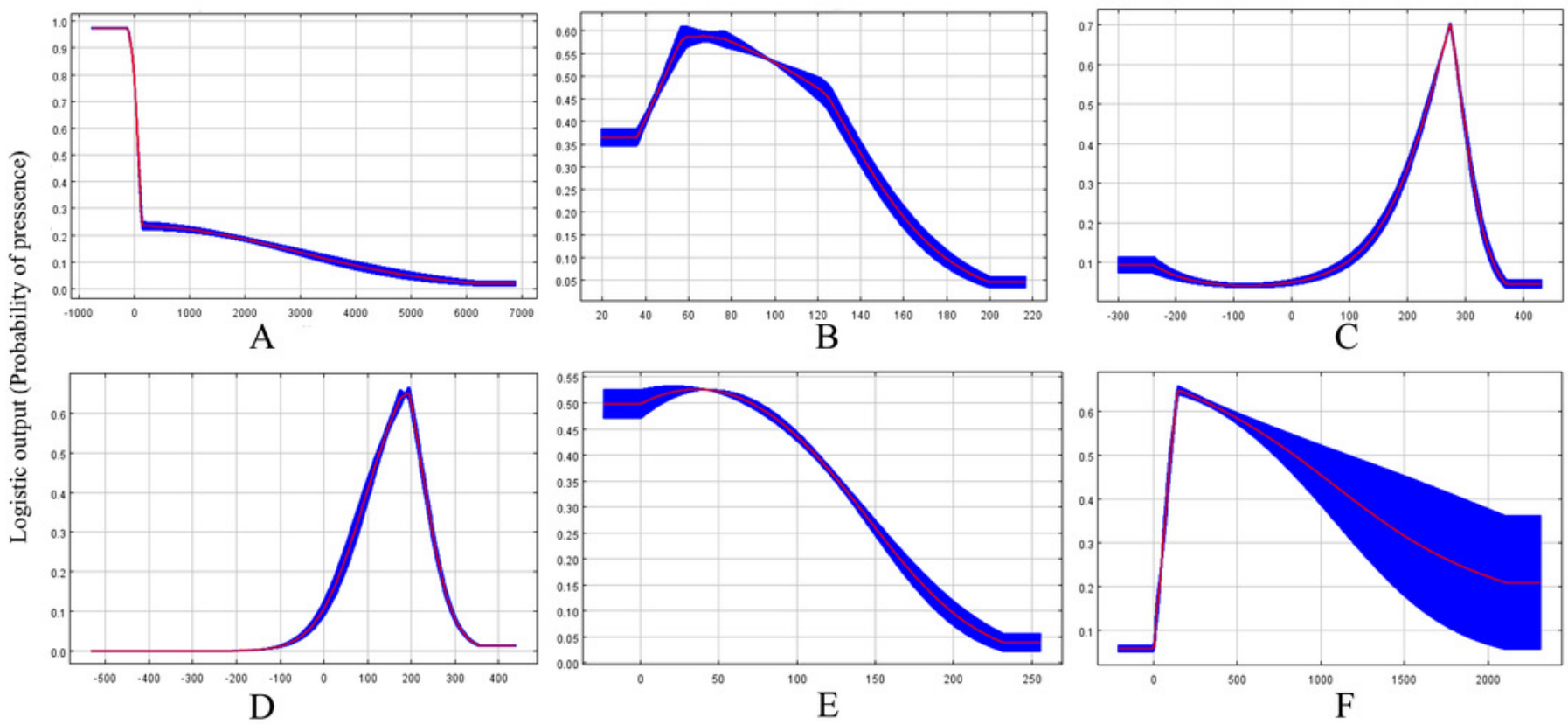


\section{Figure 3}

Future species distribution models of CAS on global scale under different climate scenarios predicted by MaxEnt

Gray = unsuitable habitat area; Blue = low habitat suitability area; Green = moderate habitat suitability area; Red = highly habitat suitability area. The base map was created with Natural Earth Dataset (http://www.naturalearthdata.com/). A=RCP 2050-2.6; B= RCP 2070-2.6; $C=R C P$ 2050-8.5; D=RCP 2070-8.5 

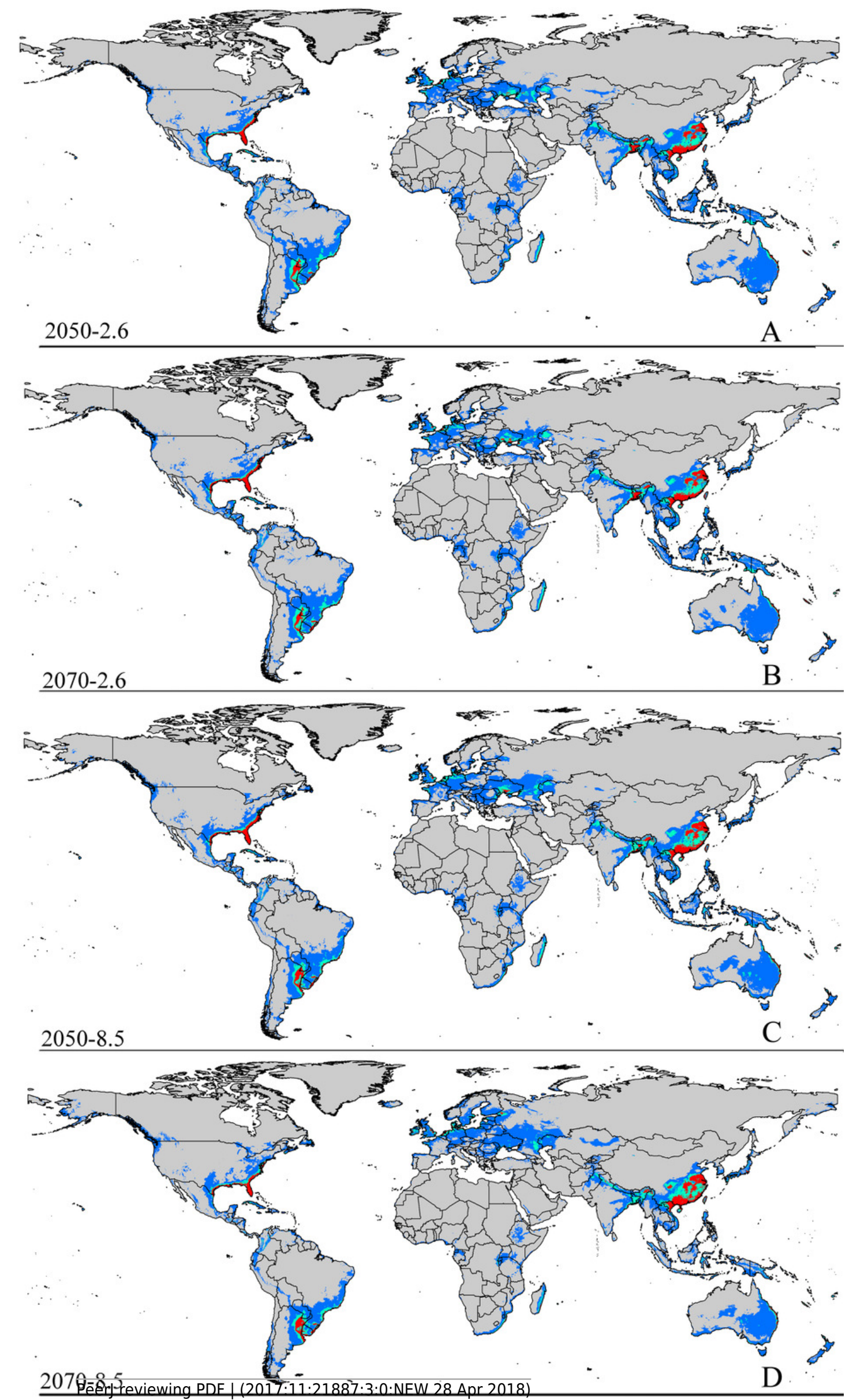